\title{
NESCoM Research Report (2019)
}

\author{
Leandro Costalonga ${ }^{1}$, Daniel José Custódio Coura ${ }^{2}$, Marcus Vinicius das Neves ${ }^{3}$, Fabiano Araújo Costa ${ }^{4}$, Helder \\ Roberto de Oliveira Rocha ${ }^{5}$.
}

\author{
NESCoM - Núcleo Espírito-santence de Computação Musical \\ Universidade Federal do Espírito Santo \\ 1,2 Campus São Mateus \\ BR 101 Km 60 - 29932-540 São Mateus, ES \\ 3,4,5 Campus Goiabeiras \\ Av. Fernando Ferrari, 514 - Goiabeiras, Vitória - ES | CEP 29075-910
} leandro.costalonga@ufes.br, daniel.coura@ufes.br, creed.mvmn@gmail.com, fabiano.costa@ufes.br,
helder.rocha@ufes.br

\begin{abstract}
The NESCOM is a multidisciplinary research center formed by musicians, engineers and computer scientists. The main research interest lies with sonology, audiotacticle musical analysis, ubiquitous music, interactive multimedia installations, and the design of computer music technology in general. Overall, the common ground for the NESCoM projects lies with the human-aspects, both cognitive and motor, behind a musical activity. This can come, for instance, in the shape of an audiotactile analysis of musical interaction applied to a new digital musical interface designed to overcome human physical constraints or the composition of a cinema soundtrack based on perceptual models of the audience. In this paper, it is reported a short description of the ongoing projects of the NESCoM and the future works.
\end{abstract}

\section{Introduction}

In 2010, the Computer Music Committee (CECM) of the Brazilian Computing Society (SBC) approved Vitória-ES as the host city of the XIII Brazilian Symposium on Computer Music (SBCM). At that time, there was little organized research initiatives in the field happening at the local universities. Moved by the necessity to organize such event, an interinstitutional local committee was formed. The relationship between the host institutions grew stronger during the process of organizing such event, up to a point that some of researchers decided to collaborate more extensively soon after the event - the NESCoM was born. However, it was not until 2013 that it was officially registered as a formal research group of Federal University of Espírito Santo (UFES) at CNPq. The group is formed by musicians, electrical engineers, and computer scientists. The members are mainly spread between the Music Department (Campus Goiabeiras/Vitória-ES) and the Computing and
Electronics Department (Campus São Mateus-ES). Despite the challenges of the remote collaboration, being geographically apart gives us the opportunity to stretch out to a vaster audience and to serve students (undergrads and postgrads) from different degrees, such as: music, computer science, computer engineering, and electrical engineering.

The main research lines are: soundtrack composition and sound-design for cinema and digital games, audiotactile musical analysis and applications, interactive multimedia installations, ubiquitous music, and new interfaces for musical expression, as detailed and exemplified by the ongoing projects.

\section{GEXS - The Sound Experimentation Group}

The Sound Experimentation Group (GEXS) emerged in 2011 with the creation of Atari Sound Perfomance (ASP), a partnership between Marcus Neves founder of GEXS - and the sound artist Herbert Baioco, who was at that time a substitute professor of the Music Course of UFES.

The Atari Sound Perfomance (ASP) used circuit bending technique to perform real time audio and video processing using an old Atari video-game. The ASP was presented in Festivals in Rio de Janeiro, Paraná, São Paulo and Espírito Santo. In 2012, with the participation of three students of the course, was created the first sound installation, (en) roll, exhibited in May of that year at Galeria Universitat Universitario of UFES.

In 2013 the group restructured itself during the first semester and resumed activities from August of that year. Two lines of work were established: [1] Study and creation of individual and collective performances within the field of Experimental Music and Sonic Arts. In this line of work, collective performances, compositions and acoustic music concerts, and sound production for radio programs were developed. Among the performances, Brinks (2014) went beyond the limits of the academic sphere, being 
performed at the National Meeting of University Composers - ENCUn (2014), in São Paulo / SP and Fábrica.Lab (2014), in Vitória / ES. In addition to the collective practice, the development of individual musical compositions is also encouraged and later compiled into discs released annually. During the period between 2014 and 2019, several participations took place at the Electronic Language International Festival - FILE in the form of sound works and musical pieces composed by the students Joceles Bicalho, in 2015 and in 2016 in partnership Marcus Neves, and Giuseppe Cavatti, in 2019. The three pieces derived from this musical production performed within the GEXS. [2] Study of sound language for audiovisual works, especially for cinema and series; In this line we study [a] concepts, forms and techniques applied in the sectors of the production chain of the area of sound for audiovisual works: sound capture, soundtrack composition, sound effects production, sound editing, mixing and sound design; [b] film analysis of audiovisual language applied to software such as eAnalysis and iAnalysis, developed by the French researcher Pierre Couprie. From 2015 until the present day, the group has participated in several university and professional films in the audio sectors, especially in the post-production and in the composition of pre-established musical track or in the real-time performance for movie accompaniments, such as in the case of The Marriage of Clarice and Bataille (2017), by the artists Aline Dias and Júlia Amaral, who later would derive as a sound installation and radio-soap opera, and in the performance for the opening of the Sci-Fi Sesc Glória Cultural Center Festival (Vitória / ES). Some research works also derived from this axis either from the Scientific Initiation Program of UFES or in the form of papers for academic events in the area of sound and music for film and audiovisual.

This project is coordinated by Marcus Vinicius Marvila das Neves and, currently, the group consists of the following students: Yasmin Marques, Gabriel Madeira, Eduardo Buback, Gisele Bernardes, Jennifer Nogueira, Alessandra Felix, Giuseppe Cavatti, Gabriel Amorim, Dyone Cipriano, Mario Schiavini, Bruno Hanstenreiter. The professor Alexsandro Meirelles (UFES) also collaborates as an associate researcher.

\section{Audiotactile Analysis}

According to Vincenzo Caporaletti's [1], the general criterion for identifying audiotactile music is the existence of the mediological pair "audiotactile principle [ATP + neo-auratic encoding [NAE]" in the formative process of art music. This simple yet dense formula reveals that we may find, in this music's poietic dimension, important aesthetic precepts associated with groove, swing, and the propulsive and depulsive formative energy etc. Such criteria are induced by the awareness of the technological inscription and phonographic fixation of these values, and also by acknowledging the relevance of this process as a constitutive modality of music as a work of art.

This project aims to develop studies that problematize conceptual and referential aspects about improvisation, groove, and musical interaction in Audiotactile Music (jazz, rock, pop, rap, Brazilian popular music, improvised music, world music, etc. Moreover, it aims to build a database on the micro and macro structural dimension of groove in Brazilian (urban / popular) songs that are re-assignable to the taxonomic model of the songs of audiotactile expression[1][2]. In other words, it seeks to collect relevant data for the investigation of musicological problems associated with the formative processes (production and reception) of a groovy, improvisational, extemporaneous and interactional nature in the music produced in Brazil since the beginning of the 20th century, where the phonographic record is the textual status of the musical work, considering the factors intrinsic to the inter and transcultural dynamics characteristic of such processes. Specifically, we intend to analyze a corpus of phonograms produced in Brazil since the beginning of the 20th century, identifying the systematic variations of micro and macro grooves in recorded performances, for further comparative analysis in diachronic and synchronic perspective of artists and music groups. The Groovemic analysis method is based on the Integrated Analysis Model (IAM), described in Caporaletti [3]which advances in an audiotactile perspective of the Systematic Variations of Duration (SYVAR-D) paradigm described by Bengtsson and Gabrielsson[4] , but also seeks the constant updating and implementation of new protocols such as Swing Ratio [5]. The computer branch of NESCoM offers advice on the computational tools available to extract musical data, transcription by musical notation, as well as theoretical and methodological contributions of musicology (history, theory and musical analysis), ethnomusicology, popular music and Cultural Studies, articulated with the fields of philosophy, social sciences and cognitive sciences, mediatics, and anthropology.

This project is implemented by Jennifer Soares Nogueira and is coordinated by Fabiano Araújo da Costa.

\section{Digital Musical Instruments Design}

Historically, an HCI perspective is often related to concepts, models, methods and techniques whose final intention is to optimize the user interface (UI) around how people can, want, or need to work, rather than forcing the users to change how they work to accommodate the system or function. In fact, an HCI perspective is based on the needs of the users and, for that, we need to know them, their goals and tasks. In other words, to adopt an HCI perspective in computer music converges towards the central idea that, to design more useful and usable systems, we must better understand users and the tasks they undertake, and better apply our understanding of these tasks in the design process. Such approach (known as User-Centered Design, UCD) is also valuable for the design of digital devices-applications-gadgets for music.

People usually have an "emotional" affection towards their acoustic instruments and they bonded with its character [6]. This is very different in regard to people's feelings about their digital instruments and, a big part of it, is due to the user experience (UX). As the name suggests, UX design is about designing the ideal experience of using a service or product. To achieve this, the users must be in the centre of the designing process (UCD approach): they must not only be listened but also be involved. Overall, it is essential to take into account what people are good and 
bad at, both in a motor and cognitive level.

Until recently, most scholars were wary of the notion that music cognition could have a biological basis, and this fact reflects on the limited support HCI offers to the design of computer music technology. However, the growing interest from the Computer Music community in digital and computer interfaces used for music performance is a clear indication that Computer Music (CM) researchers have become aware of the importance of HCI studies. Indeed, interfaces for musical performance present immense challenges for HCI, since such interfaces provide the interaction between a performer and a computing system (involving several complex cognitive and motor skills), they make computers turn back toward being things that fit our physical, embodied natures, rather than only operating in the realm of symbolic processing. Therefore, such interfaces for musical performance should be designed around human inputs and outputs rather than computer ones [7] and this claim remains true in the context of computer music. Following, some of the ongoing projects in that particular line of research.

\subsection{TIME - Tangible Interface for Musical Education}

The project consists in building a tangible interface to test the relation between the psyche (mental processes) and motoric (physical activities) in a musical context aiming to validate some of the cognitive traits of musicality. The proposed interface is a surface, equipped with computer vision, where inexpensive non-tech materials (slime, playdough, clay, ink, etc) are freely shaped and moulded in different directions and forms. The idea is to establish natural mappings between sensorimotor/manipulation skills and sound perception in order to propose better designing guidelines to design new digital musical instruments.

Psychologists and educators have been using such materials as a tool to let the children to express and communicate ideas, thoughts and feelings; It is sensorial tactile experience that stimulate the children to respond creatively to what they see, hear, smell, touch and feel. Since the goal of the project is to gain a deeper knowledge of innate cognitive traits involved in musical activities, it has been decided that the same strategy should be used in the communication with children subjects.

This project is coordinated by Prof. Leandro Costalonga and it has been implemented by Luiz Guilherme Rodrigues Meireles and Carlos Henrique Fernandes Louzada da Fonseca, both students of the Computer Science course (CEUNES/UFES)

\subsection{Assistive Technology for Expressive Musical Performance}

According to the latest Brazilian census, around 45,6 million Brazilians (23,9\% of the overall population) declared some sort of disability. Out of this, 13.1 million are motor impaired people. In theory, there have all sort of laws granting equals opportunities to disable people. The reality is quite different though. Designing interaction for motor impaired people give us the opportunity to apply the musicality-oriented interaction design framework [8]. As a case of study, a performance tool for real-time improvisation based on mashup has been developed. The overall idea is to feed a database with musical data (audio) continuously retrieved from music streaming services, segment it based on a human-like (perceptual) rhythm pattern recognition metric and establishing a classification matching criterion to merge the samples based on the performer's actions.

It is important to realize the complexity of extracting and organizing this enormous amount of date and offers to the performer just the samples that are adequate both aesthetically and technically. This is done applying Music Information Retrieval (MIR) techniques. Equally challenging is to design the interaction between this vast database and the motor impaired performer with all the support that is required in the context of a live musical improvisation. Hence, a study about musical creation using audio segments recombination extracted from WAV files is currently ongoing - something inspired by the process of cutting and pasting of magnetic tapes used by the pioneers electroacoustic music. Some results can be listened at [https://bit.ly/2XHvbm1].

This ongoing research in a master project developed by Higor Camporez and it is supervised by Helder Rocha and Leandro Costalonga.

\subsection{Musicality-oriented programming}

In recent years, the two sides of the brain have come to symbolize two sides of human nature; the left brain hailed (or disparaged) as "logical," "analytical," and "intellectual," and the "intuitive" right brain as the avatar of emotion and creativity. The ability to produce and respond to music is conventionally ascribed to the right side of the brain [9] Interestingly, Magnusson \& Mendieta [6] reported that one of their subjects believed that acoustic instruments tended to be more right brain or spatial, and digital instruments tended to be more left brain and linguistic. Now, if you think about computer programming, there is little doubt it is associated with the left-brain side, therefore, it is safe to assume that music making using computer programming languages does not explore the same cognitive arsenal as that music composed using traditional strategies. There is no judgment regarded to their artistic value or aesthetics here, just an assumption that the current programming languages for music were not designed to consider our inner musicality.

This project aims to propose a programming language that is truly designed to support the intuitive, creative and analytical processes involved in musical activities. For that, a series of studies of the current languages and environments (like SuperCollider, ixilang, Sonic Pi, CSound, Pure-data, etc) is being held with musicians in order to assess its strong and weak points.

This project is coordinated by Prof. Leandro Costalonga and it has been implemented by Herick Lima (Computer Science, CEUNES/UFES)

\subsection{Artificial Intelligence applied to Musicality}

Csikszentmihalyi [10] argued that an intrinsically 
rewarding state of consciousness (negentropic state) is achieved when skills and challenges are in equilibrium, and music is basically done for pleasure.

The translation of musical thoughts into actions usually requires, not only talent but also a fair amount of practice. These actions can be either motor-related, such as playing a fast passage on a traditional musical instrument, or cognitive-related, such as structuring and developing a musical algorithm. To amend that, several commercial musical products offer musical libraries composed by "building blocks" (samples, patches, rhythmic patterns, etc.) as well as intelligent assistance features that facilitate the process of creating music. However, the level of the assistance offered must reflect a well-thought balance between aid and intrusiveness, since there is evidence that more knowledgeable individuals are less likely to enjoy it.

The said, this project studies ways to conciliate skills, challenges, and assistance by using AI approach, in order to offer features such as: autocomplete musical phrases, intelligent harmonizers and timbre recommendation system based on a particular musical style, performance-related assistance such as adaptive accompaniment systems or an intelligent "autopilot" mode for live coding.

This project is coordinated by Prof. Leandro Costalonga and it has been implemented by Luis Henrique Gundes Valim (Computer Science, CEUNES/UFES)

\section{Final Words}

The NESCoM is a relatively new research group, officially founded just over 6 year ago (2013). It is a multidisciplinary group formed by researchers from different departments, including computer science, computer engineering, electrical engineering and, of course, music. It is geographically located at two campi of the Federal University of Espírito Santo, with the Music and Electrical Engineering departments located and the main campus in Vitória-ES (Campus Goiabeiras) and the Computer Science and Computer Engineering at the north campus in São Mateus, just over $220 \mathrm{~km}$ away. Unfortunately, it must be acknowledged that the distance is indeed a limiting factor in the interaction and collaboration between these two branches. NESCoM is also a member of the of G-UbiMus, an international multidisciplinary research network composed by UFRGS, UFAC, IFAC, UFSJ, UFES, Maynooth University (Ireland), Linnaeus University (Sweden) e Queen Mary University of London (UK).

Over the years, the group has produced over 35 peer-reviewed papers, 5 book chapters, and a book. In addition, over 40 pieces were composed for concerts, cinema soundtracks, and audio-visual productions. Academically-wise, over 40 monographies and 3 master dissertations were written. In fact, the group is never short of engaged talented students that wish to join in.

At the moment, the group is working to improve collaboration with other research groups with similar research interests at the university, such as the [eMMa] Núcleo de Estudos em Música e Musicologia Audiotátil. Also, an ongoing project involving the Sound and Music Computing Group (University of Padova, IT) and Music
Technology Lab of Maynooth University (IR) is looking into guidelines to design more intuitive musical instruments.

\section{References}

1. Caporaletti, V.: I modelli cognitivi visivo e audiotattile: criteri epistemologici e modalità di implementazione. 5, 97-123 (2018)

2. Costa, F.A.: ARAÚJO COSTA, F. (2018) Groove and Writing in Radamés Gnattali's Toccata em Ritmo de Samba No 2. RJMA - J. Jazz Audiotactile Music. Stud. English Noteb.

3. Caporaletti, V.: Swing e groove : sui fondamenti estetici delle musiche audiotattili.

4. GABRIELSSON, A., BENGTSSON, I., GABRIELSSON, B.: Performance of musical rhythm in 3/4 and 6/8 meter. Scand. J. Psychol. 24, 193-213 (1983)

5. ELLIS, M.C.: AN ANALYSIS OF \&quot;SWING\&quot; SUBDIVISION AND ASYNCHRONIZATION IN THREE JAZZ SAXOPHONISTS. Percept. Mot. Skills. 73, 707 (1991)

6. Magnusson, T., Mendieta, E.H.: The acoustic, the digital and the body. In: Proceedings of the 7th international conference on New interfaces for musical expression - NIME '07. p. 94. ACM Press, New York, New York, USA (2007)

7. Miranda, E.R., Wanderley, M.M., Kirk, R.: New digital musical instruments : control and interaction beyond the keyboard.

8. Araújo Fim Camporez, H., Frizera Neto, A., Lesqueves Costalonga, L., Roberto de Oliveira Rocha, H.: Interface Computacional para Controle Musical Utilizando os Movimentos dos Olhos. (2018)

9. Weaver, E.: A more holistic picture.

10. Csikszentmihalyi, M.: Imagining the self: An evolutionary excursion. Poetics. 21, 153-167 (1992) 